\title{
A JUSTIÇA ENTRE O ESPÍRITO DO PERDÃO E O ESPÍRITO DA VINGANÇA
}

\section{JUSTICE BETWEEN THE SPIRIT OF FORGIVENESS AND REVENGE}

\author{
Jackson da Silva Leal*
}

\begin{abstract}
RESUMO
O presente trabalho tem como objeto de análise a Justiça em sua face criminal, a partir de duas figuras que são entendidas como arquetípicas - a Justiça Penal e a Justiça Restaurativa - e de dois elementos que são apontados como preponderantes a cada uma delas: o espírito da vingança ou retributivo, e o espírito do perdão ou restaurador. A figura da Justiça Penal estatal e retributiva-vingativa contemporânea é permeada pelo cientificismo positivista discursivamente neutro e sua dinâmica mecanicamente engessada, que engendra uma prática rotular e seletiva de exclusão social e inflição mecânica e consciente de dor aos selecionados. A figura da Justiça Restaurativa se preconiza na sua forma comunitária e não judicial, sendo, portanto, participativa, dialogal, desburocratizada. É permeada pelo espírito do perdão mútuo e tem como escopo principal a restauração do tecido social que foi rompido pela agressão. Este trabalho tem como objetivo repensar o Direito e, sobretudo, a ciência penal como vem sendo construída pelas instâncias oficiais, e demonstrar como existem alternativas para além do deserto do real que a dogmática positivista preconiza e, inclusive, para fora das suas estruturas hierarquizantes. Assim, o presente trabalho é resultado eminentemente de uma revisão bibliográfica na qual subjaz um posicionamento crítico reflexivo e pluralista comunitário.
\end{abstract}

Palavras-chave: Justiça Restaurativa. Sistema Penal. Vingança. Perdão. Pluralismo jurídico.

\begin{abstract}
This paper analyzes criminal justice considering two figures understood as archetypal - Criminal Justice and Restorative Justice. The paper also considers the two prevalent elements of each of them: the spirit of revenge or retribution and the spirit of forgiveness or restoration, respectively. The image of the contemporary state Criminal Justice and retributive-vindictive is permeated by positivist discursively neutral scientificism and its mechanical dynamic that engenders a practice of selective labeling and social exclusion and mechanical and conscious infliction of pain to those selected. The image of restorative justice advocates its community and non-judicial form, thus participatory, dialogical and unbureaucratic. It is permeated by the spirit of mutual forgiveness and aims to
\end{abstract}

* Mestrando em Política Social pela Universidade Católica de Pelotas (UCPel) e graduado em Direito pela mesma instituição. Bolsista CAPES. Email: <jacksonsilvaleal@gmail.com> 
restore the social fabric broken by the assault. This paper aims to rethink Law, in particular criminal science, as it has been built by official instances and demonstrate the existing alternatives beyond the real wilderness advocated by the positivist dogma and even out of their hierarchized structure. Thus, this work is essentially the result of a literature review with a critical reflective and pluralistic community underpinning.

Keywords: Restorative justice. Criminal justice. Revenge. Forgiveness. Legal pluralism.

\section{Introdução}

Neste trabalho se analisa a Justiça em sua faceta que se propõe a julgar os fatos que se definem como crimes ou delitos e os objetos do consequente processo persecutório (inquisitório ou acusatório) em prol de uma discursada restauração da segurança societária e de uma artificial ou fictícia definição de Justiça.

Nesse sentido, trabalha-se, neste texto, com dois modelos ou tipos ideais, dentro dos quais cabem diversas nuances e particularidades nacionais e locais, não fugindo, entretanto, dos principais traços que se apontam como distintivos de cada uma.

Fala-se da Justiça Penal que se caracteriza por sua capacidade punitiva, potencialidade e eficiência em infligir dor aos indivíduos que são definidos (julgados) como culpados; outro traço importante e distintivo dessa importante engrenagem social é que ela organiza seus procedimentos a partir de postulados rigidamente definidos e de uma estrutura hierarquizante à qual se atribui uma suposta segurança jurídica e institucional baseada em um discurso legitimante e legitimador (por uma dupla via e função) da neutralidade científica fornecida por um mecanicismo positivista dinamizado por um aparato burocrático centralizado (sistêmico).

Ao revés, fala-se também da Justiça Restaurativa (ainda que a denominação suscite interpretações diversas e até mesmo antagônicas, além de práticas que podem ser reprodutoras de sofrimento sob o manto legitimador da alternatividade), a qual é entendida como um processo genuinamente alternativo ao sistema penal oficial, pois é calcado em relações horizontalizadas e a partir de uma estrutura desburocratizada e sem a rigidez teórica, procedimental e epistêmica que caracteriza o sistema centralizado no Estado, pautando-se pela projeção do futuro e pela

(re)constituição dos laços sociais rompidos pela lesão que é social e não individual. Esse processo alternativo é operado através de dinâmicas inclusivas, responsivas, democrático-participativas e desprofissionalizadas.

Para levar a cabo essa análise e microrruptura prático-epistêmica, aponta-se e atribui-se a cada uma dessas categorias ou diferentes nuances de fazer justiça (ou construí-la comunitária e participativamente) um tipo ideal que se vincula a uma diferente entidade espiritual. Salienta-se, desde já, que não se trata de uma análise de cunho religioso ou que propugne uma abordagem espiritual que divida as práticas humanas de forma maniqueísta entre bem e mal em sua essencialidade ${ }^{1}$.

Trata-se, sim, de um constructo teórico que, em nível ilustrativo e analítico, contribui para a reflexão acerca das características que têm sido apresentadas pelas diferentes formas e dinâmicas de tratar não só os conflitos e seus autores na modernidade, mas também as possibilidades alternativas frente às quais o sistema tem encontrado dificuldade de se deparar e dialogar. Serve-se, assim, de estruturas conceituais arquetípicas e que são usadas para demonstrar, desvelar e refletir sobre os elementos preponderantes a cada uma das dinâmicas de resolução/tratamento de conflitos.

Assim, a primeira figura representa a incorporação de Zarathos ao Sistema Penal oficial e todo seu ímpeto de vingança em busca de uma suposta recomposição social, extirpando o objeto (indivíduo)

\footnotetext{
${ }^{1} \mathrm{O}$ que remete ainda, ao fio condutor do trabalho, que se estrutura a partir da análise de duas figuras espiritualizadas representativas do perdão e da vingança. Não se propõe a fazer incongruentemente o que se refuta neste trabalho - a manutenção de relações maniqueístas -, mas sim se trabalha estas figuras como diferentes posturas éticas, a partir de uma ideia de ética emancipatória para a construção e pacificação social rompendo com a gestão violenta, reprodutora e utilitarista do sistema penal e do direito.
} 
definido como mal (infrator/monstro/criminoso), projetando-se como um processo de vingança que se volta para o passado, para a violação já ocorrida, em uma tentativa (discursiva) de recomposição/reconstituição do status quo, ainda que essa seja, sabidamente, uma das falácias ou ficções jurídicas que servem mais para seu processo constante de legitimação do que para uma efetiva pacificação social.

E a figura de Zadkiel, por sua vez, busca fazer Justiça a partir do perdão; para fim deste trabalho, essa figura se associa às práticas alternativas de realizar (tais como a Justiça Restaurativa como alternativa ao sistema e as práticas de dinâmica comunitária), construir e coproduzir a justiça, objetivando a recomposição do tecido social a partir da restauração das relações humanas e comunitárias. Essa recomposição seria pautada pela ideia de diálogo e de relações dialogais horizontais, com respostas voltadas para o futuro da comunidade afetada como um todo pela agressão; e seria orientada por uma concepção de dano social e por uma dinâmica pedagógica e emancipatória, e não pela simplificadora concepção da infração de uma determinada regra imposta por um sistema de relações sociais desiguais.

Salienta-se, por fim, em sede introdutória, que este trabalho está embasado eminentemente em material bibliográfico e se pauta por um posicionamento crítico-reflexivo, tal como os trabalhos produzidos no bojo da criminologia crítica, alicerçando-se em referenciais ou constructos teóricos como os fornecidos pelos estudos do labelling aproach e a teoria do etiquetamento, em interface com as contribuições de uma macrocriminologia e inseridos, ainda, em um processo de construção e transformação social (práxis) preconizada e contextualizada a partir do pensamento latino-americano e sua realidade social, política e cultural.

Neste esforço teórico, ainda a título de aportes metodológicos, compartilha-se do desconforto de que fala a professora Vera Malaguti Batista:

É por isso que todas as definições da criminologia são atos discursivos, atos de poder com defeitos concretos, não são neutros: dos objetivos aos métodos, dos paradigmas às políticas criminais. Aqui reside o enigma central da questão criminal. [...] para entender o objeto da criminologia, temos de entender a demanda por ordem de nossa formação econômica e social. A criminologia se relaciona com a luta pelo poder e pela necessidade de ordem. A marcha do capital e a construção do grande Ocidente colonizador do mundo e empreendedor da barbárie precisam de operacionalização do poder punitivo para assegurar uma densa necessidade de ordem. Esperamos tentar aprofundar essa reflexão daqui do lado selvagem. (BATISTA, 2011, p.19 - grifos do autor).

Assim é que se propõe realizar uma abordagem e uma reflexão que intentam trazer os problemas da política criminal, em especial da jurisdição criminal, para o contexto e para as particularidades da América Latina e sua carga cultural e necessidades reais e específicas.

\section{Zarathos $^{2}$ e o espírito da vingança incorpo- rado no sistema penal do estado moderno}

Neste primeiro momento da análise aborda-se, então, o sistema contemporâneo de controle e resposta punitiva ao delito, a partir da postura oficial do Estado e pelo processo altamente burocratizado e hipercientificizado da violência legitimada por um dogmatismo positivista pseudo-humanitário e suas dinâmicas de punição/vingança que caracterizam os sistemas penais modernos.

A isso se atribui o que se denomina de processo de incorporação do espírito de Zarathos ao Sistema Penal contemporâneo, e sua tentativa de restauração do tecido social e reconstituição da sociedade fraturada (pelo menos esse é o discurso que legitima suas ações), ou do sistema dominante, e sua ânsia/ necessidade de vingança e aniquilação dos indivíduos infratores e dissidentes; ou, como diria Zygmunt Bauman (1998), de eliminação das ervas daninhas do jardim da modernidade.

É nesse sentido que se organizou o trabalho ora apresentado, analisando-se essa instituição que é o Sistema Penal como faceta do Poder Judiciário, mas não só. Ela é também composta por toda a política criminal que envolve os esforços de produção de sentido, os poderes da polícia e as instituições encarceradoras (inclusive de menores), ou seja, uma estrutura material e simbólica extremamente complexa

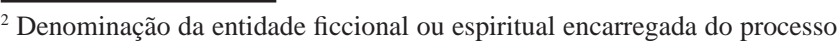
de vingança, pura e simples, por um ato de violência, como retribuição a um mal cometido; violência oficial como retribuição por uma violência privada ilegal cometida.
} 
e que encerra diversos temas de igual complexidade e necessidade de aprofundamento. Esse é o motivo pelo qual não se tem a pretensão de abordar e aprofundar essa instituição em sua totalidade - e sequer este trabalho teria fôlego teórico, espacial e cognitivo para isso.

Com isso, dá-se atenção a dois elementos ou categorias de análise que são fundamentais para o escopo e para a reflexão que se pretende neste esforço teórico e microrruptura epistêmica e prática, São eles: (i) o código de símbolos e signos com que se opera, ou o fundamento elementar epistemológico e discursivo legitimante (ou legitimador) do sistema penal burguês de viés positivista e punitivista, e sua dinâmica de criação de outros sistemas (estranhos e dissidentes); (ii) e sua estrutura de ação que se pauta por uma rígida congregação de signos e símbolos orientados por um fechado e rígido procedimento e papéis a serem adotados e seguidos fielmente por técnicos (descomprometidos) do sistema que atuam nessa trama teatral (para não dizer tragicômica - não fossem as vidas que nela se despedaçam), enquanto resta aos principais interessados o papel de coadjuvantes que ficam aguardando a sentença - ou qualquer tipo de intervenção estatal oficial policialesca - que sobre si recairá.

Nessa linha, a título de contextualização, aponta-se que se vive na modernidade pós-industrial ou pós (expectativa de) welfare state; ou, ainda, que se vive como propõe Nils Christie, que considera imperialista o modus vivendi burguês e ocidental e, assim, define o ethos burguês que se propaga como sendo o paradigma de sociabilidade ao qual se deve curvar ou adaptar:

A ideia de desenvolvimento é imperialista. Imperialista na arrogância das nações desenvolvidas, que dizem: estamos ajudando para que o ajudado se torne o que nós somos. Imperialista no fato de que a ajuda consiste no encorajamento e/ou coerção dessas nações a abandonarem uma organização multi-institucional em favor da monoinstitucional, por intermédio da colonização de ideias e valores por apenas uma única e dominante instituição. (CHRISTIE, 2011, p. 38).

Esse paradigma de sociabilidade (ou gestão social totalitária) burguesa tem como característica precípua o império da lei e todo o seu complexo sistema de promessas e déficits que fazem parte intrínseca do paradigma positivista que impera desde o século XIX, com as suas constituições e controles. Compete à lei tanto definir os papéis políticos e sociais como regular os limites das liberdades, para que a sociedade não se transforme em uma bestialidade hobbesiana.

A partir de então, o processo de tipificação do delito e a resposta a ele passam a ocupar lugar central no paradigma de sociabilidade moderno, utilizando-se o Direito como uma ferramenta legitimada por um discurso pseudo-humanizador (que discursivamente propõe regulação do controle legal e oficial da inflição oficializada de dor como pagamento a uma suposta dívida social) permeado por uma prática técnico-mecanicista redutora de complexidades que desconsidera as particularidades e nuanças (transformadas em irrelevantes) existentes nas relações e vidas humanas heterogêneas (que passam, homogeneamente, a números de processos e precedentes jurisprudenciais).

Assim leciona Howard Becker a partir dos estudos do Labeling Approach:

O desvio não é uma qualidade do ato que a pessoa comete, mas uma consequência da aplicação por outros de regras e sanções a um infrator. O desviante é alguém a quem esse rótulo foi aplicado com sucesso; o comportamento desviante é aquele que as pessoas rotulam como tal. (BECKER, 2008, p.22).

\section{Ainda, para Nils Christie:}

O crime não existe até que seja submetido a um processo altamente especializado de atribuição de sentido e, em casos extremos, acabe como ocorrências certificadas por juízes criminais como o tipo particular de condutas indesejadas chamadas de crime. Crime é uma, apenas uma, das inúmeras formas de classificar atos deploráveis. (CHRISTIE, 2011, p.24-5).

Aponta-se, assim, para a capacidade da lei e da política criminal de criar uma realidade artificial que, para muitos indivíduos, passa a ser a única realidade existente ou que é colocada à sua disposição (ou imposta). Eles têm de suportar essa realidade e, se possível, adaptar-se a ela ou sobreviver. Como aponta o professor Salo de Carvalho (2008, p.28), "no laboratório do direito, o comportamento individual se apresenta como variável independente, 
limitando-se o processo penal à construção abstrata que separa o conflito do contexto, empobrecendo-o, pois sua fragmentação ocorre pelo recorte arbitrário da realidade".

Ao expressar suas ideias sobre a faceta performativa da lei e sobre as políticas do controle social e criminal, as quais, conforme definem e determinam alguma coisa, criam uma realidade para além das suas estruturas, condicionando os indivíduos, a professora Lola Aniyar de Castro diz o seguinte:

Esse controle social, e a dominação, podem ser evidenciados como força explicita, mas o comum é que se dê à dominação a face serena da hegemonia (entendida em sentido gramsciano de dominação mais consenso), e ao controle social a face da ideologia. Portanto, como se sabe, o poder incorpora todas as forças ideológicas ou motivações disponíveis para fundamentar-se sobre uma ampla uniformidade cultural, não só vão gerar uma ilusão de representatividade e uma ficção de participação em decisões que apenas formalmente serão políticas, mas acionarão as próprias massas na tarefa desse controle social. (ANIYAR DE CASTRO, 2005, p.93).

Na mesma linha, leciona Vera Malaguti Batista:

Utilizando amplamente o exercício do poder de sequestro e estigmatização, o verdadeiro e real poder do sistema penal não é o repressor, mas o exercício positivo, configurador, simbólico. Existe uma renúncia expressa à legalidade penal através de um controle social militarizado e verticalizado sobre os setores mais pobres da população ou sobre os dissidentes. Esse poder configurador é também repressivo ao interiorizar a disciplina, conformando uma sociedade submetida a uma vigilância interiorizada da autoridade. É fundamental o papel dos meios de comunicação de massa na introjeção dessa ordem verticalizante. (BATISTA, 2003, p.54).

Permite-se a primeira abordagem, que diz respeito ao código de símbolos e signos (no plano de uma epistemologia punitiva) que pautam as dinâmicas de controle/punição a fim de legitimar o sistema e se autolegitimar. Sendo assim, essa abordagem é caracterizadora do sistema penal moderno e suas dinâmicas simbólicas e materiais de caráter punitivista, e é permitida a partir da contribuição de Slavoj Zizek (2008). O referido autor explica que cada período da historicidade social e política é comandado ou orientado por um novo significante mestre que permite a regularidade e manutenção social ordeira, pelo menos a partir de uma orientação hegemônica.

Explicando o posicionamento de Slavoj Zizek (2008), as sociedades - como complexos não apenas normativos - baseiam-se, essencialmente, em regularidades simbólicas e de sentido, sobre as quais a sociedade se estrutura, se organiza e hierarquiza. Como aponta a professora Lola Anyiar de Castro, é um complexo de elementos a conformar o processo de controle social. Assim, a própria autora escreve:

Entendemos o controle social, portanto, como o conjunto de sistemas normativos (religião, ética, costumes, usos, terapêutica e direito - este último entendido em todos os ramos, na medida em que exercem controle reprodutor, mas especialmente no campo penal; em seus conteúdos (como em seus não-conteúdos), cujos portadores, através de processos seletivos (estereotipia e criminalização) e estratégias de socialização (primária e secundária ou substitutiva), estabelecem uma rede de contenções que garantem a fidelidade (ou, no fracasso dela, a submissão) das massas aos valores do sistema de dominação; o que, por motivos inerentes aos potenciais tipos de conduta dissonante, se faz sobre destinatários sociais diferencialmente controlados segundo a classe a que pertencem. (ANIYAR DE CASTRO, 2005, p.53-55).

Em todos os períodos históricos pode-se verificar um processo de construções simbólicas que são capazes de (ao menos discursivamente) devolver uma suposta regularidade e harmonia perdidas por algum processo também histórico e cíclico de conturbação social e transformações mais ou menos intensas, modificadoras e tensionadoras da pseudo ou programada regularidade sistêmica.

Nessa dinâmica surge o novo significante mestre que tem orientado a modernidade recente $-\mathrm{a}$ criação do outro - como espectro que corporifica a origem de todos os males da modernidade, ou pelo menos dos males que justificam os discursos e, sobretudo, as práticas de gestão social punitivista.

Essa ideologia é disseminada e patrocinada pelas agências morais em que se inserem os discursos punitivistas e as propostas de lei e ordem como novo significante mestre que restauraria a harmonia sistêmica/social, a partir das dinâmicas de criação dos outros, dos hostis de que fala Eugenio Raul Zaffaroni (2007, p.23): 
O inimigo declarado (hostis judicatus) configura o núcleo do tronco dos dissidentes ou inimigos abertos do poder de plantão, do qual participarão os inimigos políticos puros de todos os tempos. Trata-se de inimigos declarados, não porque declarem ou manifestem sua animosidade, mas sim porque o poder os declara como tais: não se declaram a si mesmos, mas antes são declarados pelo poder.

Esses inimigos declarados seriam responsáveis por todos (ou quase todos) os males sociais da sociedade moderna de consumo. Na mesma esteira, escreve Jock Young:

Para criar um bom inimigo, temos que ser capazes de nos convencer: 1 - que eles são a causa de grande parte de nossos problemas - senão de todos; 2 - que são intrinsecamente diferentes de nós: que resumem a corrupção, o mal, a degradação, etc. Isto é apontar precisamente o objeto e essencializar. O primeiro princípio faculta dirigir a animosidade contra eles, o segundo dá permissão para usar a violência, frequentemente de natureza extrema. (YOUNG, 2002, p.173).

Assim, entende-se essa questão de maneira diferente de alguns teóricos e pesquisadores que consideram ter sido o crime desprovido de seu componente político na modernidade recente. Entretanto, vê-se que esse componente político encontra-se latente, tendo em vista que no processo simbólico de definição do crime as dinâmicas de combate têm sido caracterizadas por um forte componente de classe em uma batalha contra os estranhos (os membros bárbaros que não querem ou não podem ser admitidos nesta sociedade de consumo). Essa é uma dinâmica segregacionista e seletiva que permeia todas as ações oriundas de uma episteme burguesa e hegemônica, assim como têm sido construídas as dinâmicas de política criminal, pautadas por um forte elemento de seleção, aniquilação e adestramento no modus vivendi burguês.

Faz-se, assim, do crime, ou melhor, da conduta desviada, um fenômeno íntima e imanentemente político, tendo em vista que se trata, ainda, de uma política criminal que se direciona para uma classe em detrimento das condições dignas de vida de outra, poder-se-ia dizer, em um tosco ou grosseiro materialismo dialético, ou economia desigual das trocas simbólicas. Assim, aponta o professor Alessandro Baratta:
O sistema de justiça criminal da sociedade capitalista serve para disciplinar despossuídos, para constrangê-los a aceitar a moral do trabalho que lhes é imposta pela posição subalterna na divisão de trabalho e na distribuição da riqueza socialmente produzida. Por isso, o sistema criminal se direciona constantemente às camadas mais frágeis e vulneráveis da população: para mantê-la - o mais dócil possível - nos guetos da marginalidade social ou para contribuir para a sua destruição física. Assim, fazendo, o sistema sinaliza uma advertência para todos os que estão nos confins da exclusão social. (BARATTA, 2003, p.15).

Seguindo na presente análise, traz-se a segunda categoria em que se trabalha o procedimento técnico-judicial moderno para apuração e punição dos fatos definidos pela legislação como delitos/crimes, onde se analisa a prática que se propõe (como a única possível e apta), responsável pela reconstituição do tecido social.

Nesse sentido, verifica-se que a Justiça e a Política Criminal têm se pautado por uma estratégia ou por uma episteme fortemente marcada por ser um referencial alienígena (descontextualizado e importado) positivista, que, apesar de todo o avanço científico e, sobretudo, da capacidade analítica e das contribuições da criminologia crítica, tem se mantido como referencial epistemológico preponderante com suas verdades inabaláveis.

Nessa linha, a prática punitivista administrativa ou judicial se pauta por dinâmicas mecânicas eficientes para o fim a que se propõem - o combate ao crime -, como sendo a sua medida de pacificação social os elevados índices (e sempre crescentes) de encarceramento definitivo ou provisório de adultos e menores, em uma nítida orientação numérica reducionista e segregadora.

Assim, essa dinâmica punitivista pura e simples atua voltando-se sempre para um passado que supostamente poderia (ainda que isso seja praticamente inconcebível) ser reconstituído, preconizando a reorganização do status quo através da retribuição pela pena/sanção, o que sanearia a sociedade fraturada.

François Ost, remontando a Franz Kafka, fala sobre essa necessidade de memória que alimenta o sistema punitivo, para, assim, a partir da obtenção dessa almejada e fictícia verdade real, reconstruir a harmonia social, retirando o infrator da sociedade: 
No capítulo VII do Procès, Kafka tem esta frase terrível: o tribunal nunca esquece nada. Um tribunal que nunca esquece nada, haverá sinal mais revelador de uma sociedade virtualmente totalitária? Mas uma memória infalível não é apenas ameaçadora, ela é igualmente ineficaz: uma personagem de Borges, chamada Funes Memorioso, é dotada de tal memória universal (tenho mais lembranças sozinho do que podem ter tido todos os homens desde que o mundo é mundo), sofrendo de insônias e febril, é capaz de reconstituir, uma a uma, todas as lembranças e todas as sensações de cada dia; em compensação, é incapaz de formular uma ideia geral - de facto, ele não pensa, ou pouco pensa, pois - pensar é esquecer diferenças, é generalizar, abstrair. (OST, 1999, p.162).

Verifica-se que esse paradigma e essa ideologia da lei e ordem que imperam na modernidade tardia podem criar e recriar inimigos, sempre difusos, disseminando assim o medo que transforma cada indivíduo em um possível policial (ou detrator, ou um simples nervo óptico a ser usado como testemunha e a difundir e transformar o poder/saber penal em omnisciente e omnipresente); ou, mesmo, que transforma cada indivíduo em propenso infrator, requerendo, a cada dia, que se refaça e seja aprovado no teste da pureza pós-moderna ao qual se referia Zygmunt Bauman (1998), sob pena de passar ao contingente dos indivíduos supérfluos no incessante processo de reciclagem/descarte humano.

Ainda, tal dinâmica positivista - que é propalada como sendo um marco de outorga ou conquista de garantias, de controles e liberdades - é, na realidade, o grande encerramento epistemológico para fora do qual não há nada, pelo menos nenhum saber que se reconheça como válido. Portanto, nada existe em termos de relevância para essa ciência jurídica que transforma todo o saber comum em irrelevante jurídico, ou em algo cientificamente insubsistente sendo um verdadeiro deserto do real.

Tal deserto se propõe como o ápice da razão humana e humanitária que dá por conquistadas as garantias materiais e processuais a partir do mero fato de insculpir em definições legais/constitucionais a liberdade e a democracia que ficam encerradas nesses textos inertes, que são defendidas com princípios, políticas e definições gerais, abstratas, genéricas, que são aplicadas homogeneamente à heterogeneidade humana e relacional, que tem as suas particularida- des desconsideradas sob pena de ver se perder a sua pseudorregularidade jurídico-procedimental. Nessa linha, leciona Nils Christie:

Portanto, a lei formal não pode levar tudo em consideração. Torna-se necessário eliminar a maioria das circunstâncias que orbitam o ato para que se possam criar casos presumidamente iguais ou análogos. A esse processo se dá o nome de eliminar o que é irrelevante. Mas definir o que é irrelevante é uma questão de juízo de valor. Para criar a igualdade, é, pois, necessário criarem-se regras para a irrelevância. Trata-se de uma irrelevância dogmaticamente definida. (CHRISTIE, 2011, p.119).

O Sistema Penal do Estado Moderno é uma complexa estrutura de símbolos e signos que se propõe como totalizadora (sendo assim arrogantemente totalitária) do conhecimento, abarcando todos os elementos que importam para a dinâmica de sociabilidade e gestão burguês-capitalista, sendo este componente epistemológico de particular perversidade a legitimar/mascarar as reais dinâmicas de desumanização de seres - transformando-os em vida nua, como propunha Giorgio Agamben (2007), a suportar legítimos processos de assassínio oficializado como meros expedientes ou baixas colaterais.

Tal paradigma pauta-se por um rigor técnico-mecanicista, uma verdadeira burocracia weberiana que se justifica em uma pseudoneutralidade axiológica e científica falaciosa, quando, em realidade, é procedimentalizada tendo uma classe de indivíduos no polo dos operadores e a outra no polo dos objetos de intervenção estatal oficial, como meros repositórios do saber/poder oficial que deve ser introjetado, sob pena de violenta punição.

No polo dos operadores, verifica-se um verdadeiro processo de introjeção do discurso da neutralidade científica e axiológica e uma suposta autolegitimação dos papéis a serem assumidos, isentando-se os sujeitos que os praticam das consequências de tudo isso, tendo em vista que fazem parte de um sistema maior, de uma máquina de engenharia social que, isoladamente, eles não podem suportar. É adotada, então, essa capa tranquilizadora do descompromisso dos operadores para com os objetos de intervenção, remontando o tradicional imperativo positivista da separação entre sujeito e objeto. Nessa linha, aponta Howard Zehr: 
Os principais tomadores de decisão (advogados, promotores, juízes, oficiais de condicional) são estimulados a se enxergarem como executores da lei que estão cumprindo um dever. Eles são levados a atribuírem a responsabilidade pelo desfecho do caso como sendo do sistema. Isto significa que aqueles que fazem justiça podem negar uma responsabilidade pessoal pelos resultados. Igualmente, não são estimulados a reconhecer aquilo que têm em comum com os ofensores enquanto seres humanos. (ZEHR, 2008, p.70).

Ainda, assim leciona a professora Lola Anyiar de Castro:

Nas sociedades contemporâneas, segundo Horkheimer, existe o império da razão instrumental, isto é, uma única preocupação com a resolução dos problemas técnicos entre meios e fins, sem a análise da racionalidade dos fins. Os indivíduos internalizam a razão instrumental e se identificam com os interesses tecnicistas do sistema. O positivismo é a consagração teórica dessa razão instrumental, não só porque utiliza a metodologia das ciências naturais, mas porque faz dessa metodologia o único critério de cientificidade e de verdade. (ANIYAR DE CASTRO, 2005, p.61).

Na mesma esteira teórica, Vera Malaguti Batista desnuda a falácia técnico-mecanicista na qual foi mergulhada e da qual retira a sua retrolegitimação, ao passo que descarta vidas humanas e adestra tantas outras ao seu modus vivendi burguês:

Trabalhamos as representações expressas por estes agentes e determinadas pelos interesses que as forjaram, e que apesar do discurso técnico não são nada neutras. Estes quadros técnicos, que entram no sistema para humanizá-lo, revelam em seus pareceres (que instruem e têm enorme poder sobre as sentenças a serem proferidas) conteúdos moralistas, segregadores e racistas, carregados daquele olhar lombrosiano e darwinista social [...] afirma que os graus de aplicação da violência nas escolas, famílias, fábricas, hospitais e prisões dependerão da necessidade de ocultá-la ou disfarçá-la. Nossos sistemas, a concessão de poder aos técnicos disfarça a violência, mistificando-a através do tecnicismo, cujo objetivo é fazer com que o objeto da violência se adapte sem chegar a ter consciência e sem reagir. Sua função é ampliar as fronteiras da exclusão, descobrindo tecnicamente novas formas de infração e produzindo a ação técnica reparadora, que adapte os indivíduos à aceitação de sua condição de objetos de violência, perpetuando o processo de violência global. (BATISTA, 2003, p.117).

Esse paradigma de sociabilidade ou de punitivismo que se apregoa como sendo a conquista do controle da punição, humanizando-a, a teria como sendo a ultima ratio da lei penal e do sistema criminal. Não obstante o que é difundido teórica e falaciosamente assiste-se a uma escalada nos índices de encarceramento e uma paulatina deterioração das condições de encarceramento, legitimado pelo medo difuso e por uma suposta elevação da criminalidade.

Contrariando esse discurso legitimador, Salo de Carvalho (2010), em ampla pesquisa realizada a partir de dados fornecidos pelo Departamento Penitenciário Nacional (DEPEN), desnuda a questão. Ele demonstra que embora o encarceramento tenha dobrado o seu número em um lapso temporal de dez anos - em 1997 havia 108,36 presos e em 2007 passou-se a ter 228,06 presos (para cada 100.000 habitantes) - o índice de homicídios no mesmo período (de 1997 a 2007, para cada 100.000 habitantes) teve variações insignificantes, ficando entre 24,2 homicídios no ano de 1997 e tendo seu ápice no ano de 2003, com 28,16 homicídios. Tais dados deixam claro o discurso falacioso do suposto aumento da criminalidade para justificar o incremento do controle e da punição, dos poderes de polícia e do aumento do encarceramento de forma significativa ${ }^{3}$.

A partir de discursos fáceis e sem correspondência com a realidade, ressurge, se transmuta e se legitima a imperiosidade do encarceramento que tem sido a regra, e não a exceção; contrariamente ao que propõem a legislação, a doutrina (dogmática) e os discursos pseudo-humanitários, Howard Zehr diz que "a privação da liberdade não é um último recurso que deve ser ponderado e justificado pelo juiz que a impõe. Pelo contrário. A prisão é normativa, e os juízes sentem a necessidade de explicar e justificar as sentenças que diferem da privação da liberdade”. (ZEHR, 2008, p.34).

Nesse sentido, pesquisa publicada pelo professor Salo de Carvalho (2010) demonstra o ímpeto punitivista dos magistrados que externam ser favoráveis a medidas que ampliam a punição, o encarcera-

\footnotetext{
${ }^{3}$ Pesquisa mais detalhada e na íntegra publicada em: CARVALHO, Salo de. O papel dos atores do sistema penal na era do punitivismo. Rio de Janeiro: Lúmen Juris, 2010.
} 
mento ou a internação, assim como o rigor policial, investigatório e processual. Segundo os dados coletados, 61\% dos magistrados revelam ser favoráveis à diminuição da maioridade penal; 75,3\% são favoráveis ao aumento do período de internação do menor infrator; 73,8\% estão de acordo com o aumento do lapso temporal para cumprimento de regime (o critério de aumento também se verifica para a liberdade condicional); 69,1\% concordam com o aumento do tempo máximo para cumprimento da pena de prisão [... $]^{4}$. Para Aniyar de Castro (2005, p.75), “ante essa escalada do autoritarismo democrático, a criminologia estigmatizadora adquire uma relevância funcional. É a luta do mal contra o bem. O anjo exterminador justiceiro não carece de legitimação”. Na mesma linha Salo de Carvalho fala sobre essa dinâmica de engenharia e gestão social através das dores oferecidas e infligidas pelo sistema penal, o que chama de mnemotécnica - sendo o que instrumentaliza as dinâmicas do espírito da vingança e da violência oficializada:

Essa técnica de memorização identificada nos castigos, fundamental para a construção do marco civilizatório (pacto social) deve necessariamente conter algo de bárbaro e violento. Essa prometeica tarefa, organizar população errante, não pode ser levada a cabo senão por meio dos mesmos recursos bárbaros cujo emprego torna possível a criação da memória: a crueldade e a violência [...] o sistema de punitividade, neste quadro, manteria presente na humanidade a necessidade de satisfação das dívidas e da culpa moral. O castigo, instrumento de moralização e normalização, através da mnemotécnica ritualizada dos processos de culpabilização, faz presente e eterno o delito. (CARVALHO, 2008b, p.75; 77).

Nesse ínterim, atribui-se à complexa estrutura material e simbólica chamada Sistema Penal o fato de estar possuída pelo espírito da vingança, tendo em vista que, tanto simbolicamente quanto materialmente, sua atuação é marcada por um procedimento higienista, extirpando da sociedade os indivíduos a quem se confere o rótulo de transgressores com eficiência, recaindo sobre eles todo o rigor que o Estado Democrático de (anti-) Direito permite ou concebe,

\footnotetext{
${ }^{4}$ A pesquisa na íntegra está publicada em: CARVALHO, Salo de. O papel dos atores do sistema penal na era do punitivismo. Rio de Janeiro: Lúmen Juris, 2010.
}

ainda que pela via transversa da corrupção, desvio funcional ou mesmo incapacidade sistêmica; ou simplesmente pela via legítima(da) oficial do monopólio do poder/dever de punir que encontra guarida nos discursos e nas políticas periculosistas.

A esse estado de coisas (materiais e simbólicas) o Direito tem servido como complexa e eficiente máquina de engenharia e controle social, como estrutura legitimada para determinação de culpados (hostis judicatus), a partir de definições supostamente construídas por uma democracia menos que formal. Os indivíduos considerados culpados são levados à expiação por processos defendidos como humanitários e permeados por garantias [até excessivas, como demonstra a pesquisa de Carvalho (2010)], realizando-se assim um verdadeiro processo de vingança estatal oficial.

\section{Zadkiel $^{5}$ e o espírito da justiça conjurado pelas práticas alternativas de juridicidade e tratamento de conflitos}

Seguindo nesta análise, reafirma-se o entendimento da importância e potencialidade emancipatória de um possível e alternativo paradigma de juridicidade, entendido como complexo simbólico/ material culturalmente determinado, no qual subjaz a potencialidade de emancipar os indivíduos. E essa emancipação não é realizada meramente como dinâmica regulatória das relações, mas transitando entre a sua faceta reguladora opressora e vingativa, a qual se pretende exorcizar, e conjurando o espírito da indulgência que permite a emancipação e o empoderamento, conforme o uso ou a cultura propicie e potencialize.

Neste ponto da abordagem se privilegiam formas alternativas de resolução de conflitos, mormente o caso da Justiça Restaurativa, como dinâmica privilegiada na seara de conflitos de natureza criminal, não se adotando uma perspectiva essencializadora acerca das condutas. Entende-se, assim, que essa dinâmica se presta a analisar e realizar juízo cognitivo sobre atos que ocasionem violência contra a pessoa,

\footnotetext{
${ }^{5}$ Figura ficcional representada por uma entidade espiritual ou angelical que se presta a possibilitar orientação e projeção de futuro, assim como também expressa o ímpeto da benevolência na gestão dos conflitos interpessoais, que não interpõe violência com violência, mas sim com o diálogo e com a restauração das diferenças.
} 
sendo esta (violência) adotada como qualquer ato que imprima/imponha sofrimento ao indivíduo objeto da ação ou omissão, podendo, assim, ser de índole pessoal/física, mental/psíquica ou material/pecuniária.

Assim, partir da conjuração do espírito, ou do arcanjo Zadkiel para as dinâmicas de juridicidade permite uma mudança profunda nos pressupostos epistemológicos e nas dinâmicas de procedibilidade da Justiça, voltando-se esta para o futuro (e não mais para o passado inerte e imodificável) e para a construção ou restauração do tecido social a partir do perdão.

Nessa linha, François Ost leciona sobre as potencialidades transformadoras do perdão e da capacidade humana em relação a ele:

Aqui estão seguramente dois polos essenciais da regulação jurídica do tempo social: o perdão, entendido em sentido amplo, como essa capacidade da sociedade para saldar o passado: ultrapassá-lo ao estabelecê-lo, libertá-lo destruindo o ciclo sem fim da vingança e do ressentimento; a promessa, por outro lado, entendida em sentido amplo, como essa capacidade da sociedade para creditar o futuro, comprometer-se em relação a ele por meio de antecipações normativas que balizarão doravante o seu desenrolar. Contra o encadeamento cego da fatalidade, a sociedade estabelece o acto absolutamente inédito e imprevisível do perdão, dando assim, se é que podemos dizê-lo, um futuro ao seu passado [...]. (OST, 1999, p.42).

Assim, não se propõe o esquecimento do passado, e sequer se entende que o perdão a que Ost se refere parte dessa premissa; mas, sim, que o perdão exorciza a agressão e seu ímpeto de vingança (pública ou privada) e permite à sociedade voltar a se projetar para o futuro, não se resumindo a ficar rememorando o passado com uma maior, menor ou fictícia fidedignidade, como geralmente fazem os indivíduos diretamente e indiretamente envolvidos na agressão: a vítima, que não terá suas dores sanadas com a punição do agressor (e sequer terá o que perdeu de volta); e o agressor, que não será mudado, apenas passando a vítima da vingança pública ao ingressar no sistema prisional, como largamente se tem podido assistir, ficando, assim, todos os envolvidos como que presos e encerrados em um passado imutável, encapsulados naquele evento danoso que não é passível de desfazer.
Salo de Carvalho (2008b) alerta para a concepção de perdão como uma rememoração do passado que não morre, de um passado que não termina, mantendo o indivíduo encerrado no evento. Sendo assim, mais uma vez o indivíduo é objeto da cognição do Estado centralizador; neste caso, não pela via da intervenção, mas mais pela via da reafirmação simbólica da superioridade, concedendo a sua remissão, o seu perdão, que pode atuar como punição - ainda que imaterial - através da indulgência e da bondade do Estado.

Entretanto, não é desse perdão que se faz referência no presente trabalho, não é de um perdão que parta da centralidade estatal ou de um procedimento técnico-mecanizado que Salo de Carvalho associa à mnemotécnica (2008b). Não é um instituto jurídico que prevê a possibilidade de perdão, quando se faz desnecessária a intervenção punitiva, mas uma dinâmica democrática e dialogal, que traz para sua trama os próprios envolvidos que foram encerrados e perdidos na trama estatal da busca da sua verdade real - da que lhe serve como sistema. Como o próprio Salo de Carvalho (2008b, p.89) afirma, “a vontade de verdade (vontade de sistema), eleita como fim último da própria atividade, revela a incapacidade de diálogo; a incapacidade de escuta das angústias das partes envolvidas nos conflitos", sendo, assim, uma vontade de saber-poder - uma vontade de sistema totalizante. Assim escreve o referido autor:

A permanência do estilo inquisitivo calcado na investigação da verdade, suavizado pela inversão ideológica do discurso liberal humanitário, alimenta o sonho narcísico dos sujeitos processuais, de extração, através dos mecanismos de prova, de dados que reconstruam o fato pretérito em precisa correspondência com aquela realidade distante. A aspiração de encontrar adequação simétrica da realidade passada (fato-crime) nos autos, a partir dos elementos probatórios a reger a ciência processual penal: a verdade real. (CARVALHO, 2008, p.84).

A partir disso, trabalha-se com o perdão como dinâmica construída entre os envolvidos direta e indiretamente com o fato e com a comunidade que também é interessada na resolução de conflitos. Fala-se, assim, de resolução alternativa do conflito, a qual é usada - não pela via criminal - como forma de libertação, de emancipação, de ultrapassagem do 
próprio conflito. Remonta-se, assim, o que Jacinto Nelson Miranda Coutinho denomina de caso penal, substituindo-se o fato-crime (referido por Salo Carvalho, 2008 b), trabalhando-se com uma refundação e reentendimento do caso de forma material, simbólica e cognitiva, de maneira partilhada e horizontalizada.

Sendo assim, o perdão projeta as relações entre os indivíduos para o futuro, para reatá-las e para a reestruturação das vidas desses indivíduos, deixando o passado em seu devido lugar e como lembrança (ainda que dolorosa). Assim, faz-se uso novamente das palavras de François Ost:

Ao contrário de todos esses substitutos, o perdão é simultaneamente um acto de memória e de remissão: apagamento deliberado de uma ofensa real [...] assim o homem do ressentimento (a vítima) e o homem do remorso (o culpado) libertam-se conjuntamente de um passado obsessivo e mostram-se disponíveis para um futuro de novo prometedor: $o$ perdão é uma espécie de cura da memória, escreve Ricoeur: libertada do peso da dívida, a memória está livre para grandes projectos. O perdão dá um futuro à memória. A natureza dialectica do perdão surge assim à plena luz, já que a montante remete para a memória (a falta não é esquecida, mas reconhecida e assumida) e a jusante desemboca na promessa (a aposta confiante num outro cenário de futuro). (OST, 1999, p.174-5).

Nessa perspectiva, para efeito deste trabalho, entende-se que se subverte o paradigma judicioso oficial a que se atribui uma função meramente utilitarista para os indivíduos envolvidos no fato, os quais são, respectivamente, rotulados como infratores e como delitivo, recaindo sobre eles o processo e toda sua estrutura material e simbólica autoritária e opressiva.

Assim, rompe-se com a dinâmica em que esses indivíduos, ao invés de servirem para a restauração da comunidade em suas relações fraturadas, com seus saberes relevantes e suas experiências, servem apenas para legitimar o falacioso processo inquisitório de perquirição de culpa e busca de uma suposta verdade ficcionalmente real para satisfazer o ímpeto vingativo imperante no dever de punir do Estado (na figura do Poder Judiciário), atribuindo rótulos de agressor e vítima como espectros identificadores dos indivíduos, transformando-os em meros objetos de intervenção técnico-mecânica objetificante. Na mesma linha analisa e leciona Eugenio Raul Zaffaroni:

Com frequência instrumentalizam-se vítimas ou seus parentes, aproveitando, na maioria dos casos, a necessidade de desviar culpas e elaborar o dolo, para que encabecem campanhas de lei e ordem, nas quais a vingança é o principal objetivo. As vitimas assim manipuladas passam a opinar como técnicos e como legisladores e convocam os personagens mais sinistros e obscuros do autoritarismo penal völkisch, num espetáculo vergonhoso para a democracia e a dignidade da representação popular. (ZAFFARONI, 2007, p.75).

Nas dinâmicas que se propugnam como Justiça Restaurativa em sua vertente comunitária, se atribuem e se reconhecem os principais, indiretos e tangentes envolvidos, trazendo-se, sobretudo, seus saberes para a trama/centro do processo de diálogo.

Nessa linha, passa-se a trabalhar e apresentar alguns dos principais postulados ou estruturas conceituais que permitam à Justiça Restaurativa se fazer como uma estrutura material e, principalmente, simbólica alternativa ao sistema oficial estatal opressivo/vingativo. Como propõe Jock Young (2002, p.50), “precisamos de políticas que partam da margem e vão tão longe quanto seja aceitável (o que significa um longo caminho a percorrer), em vez de políticas que partam do centro e vão tão longe quanto seja caridoso (que não é tão longe).” O autor aponta, claramente, a necessidade de extrapolar a política e a episteme que se tem produzido a partir da centralidade oficial, com suas limitações práticas e simbólicas. Considera necessária uma política de tratamento de conflitos que, partindo de fora, da origem, dos principais interessados e afetados pelos conflitos, extrapole essas limitações e as pseudorresoluções que, a partir do centro, têm resultado em punição pura e simples (vingança oficial) e também em vitimizações secundárias e de toda ordem. Assim também escreve Eugenio Raul Zaffaroni:

Há muito se reconhece que a ameaça de infligir dor àqueles que desobedecem está na base do sistema jurídico moderno. A essência do Estado é muitas vezes descrita por cientistas sociais como o legitimo monopólio da violência. [...] as instituições e métodos do direito são, assim, partes integrantes do ciclo de violência ao invés de uma solução para ela. (apud ZEHR, 2008, p.74). 
Howard Zehr e Barb Towes (2006) trabalham no sentido de subverter um dos principais monopólios que têm possibilitado a manutenção da Justiça como figura burocrática e opressora, meramente como ferramenta legitimadora de um suposto Estado de Direito - o ato de fala, sendo esta uma das principais profanações a que se pode submeter o paradigma de juridicidade moderna. Nesse sentido, afirmam os autores:

O que estamos aprendendo com a justiça restaurativa é que um elemento fundamental da justiça está relacionado com a criação de sentido. A justiça é feita quando o sentido do crime é construído a partir das perspectivas e experiências daqueles que foram mais afetados por ele: a vítima, o infrator e talvez os membros da comunidade. Esse sentido não pode ser imposto por especialistas ou representantes externos, é necessário que a voz das vítimas, bem como a dos infratores, seja ouvida diretamente. Requer-se, para isso, uma reorganização completa de papéis e valores. Os profissionais do campo da justiça e os membros da comunidade passam a assumir a função de facilitadores, ao passo que as vitimas e infratores passam a ser os atores principais. (ZEHR; TOWES, 2006, p.419).

Tem-se como um importante elemento o princípio da não neutralidade, diferentemente do que propõe a matriz positivista que tem orientado a juridicidade estatal oficial. Preconiza-se, assim, esse princípio pelo compromisso com o resgate do tecido social através da resolução do conflito, e pelo compromisso em devolver à sociedade essa resolução. A profanação do monopólio da fala, do dizer, constitui um pressuposto fundamental para uma juridicidade alternativa.

Assim, permite-se permear as práticas restaurativas e de juridicidade comunitária de falas profanas, humanas, comuns, saindo da seara eruditamente tecnicista, burocratizada e descompromissada da ciência, que tem operacionalizado o direito até a modernidade e, assim, legitimado as atrocidades a partir de uma discursividade de (pseudo) neutralidade. Essa proposição remonta a Boaventura Santos, que escreve:

Cuando una persona se expresa oralmente, sus palabras jamás pueden divorciarse completamente de la persona misma. Esto sucede incluso en las ocasiones en que las palabras son escuchadas por tes- tigos, quienes luego las confrontarán con el emisor del mensaje respectivo debido al carácter plástico y transitorio del medio de comunicación. Pero las palabras escritas, de otra parte, crean una distancia entre el autor del mensaje y la manera en que ese mensaje se expresa, entre una afirmación de la voluntad personal y un fetiche impersonal que adquiere vida propia. Esta distancia, que recuerda mucho al mito del aprendiz de brujo, cuenta con dos dimensiones relacionadas dialécticamente. Por una parte, está la autonomía del compromiso escrito y la posibilidad de emplearlo contra la propia persona que realiza ese compromiso. Por la otra, existe un sentimiento de alienación experimentado por la persona ante su propia creación, un sentimiento de desposesión y, por lo tanto, de impotencia para afrontar y controlar el compromiso como propio. (SANTOS, 2010, p.143).

Assim, o (re)empoderamento do ato de fala, do diálogo, pode ser talvez o grande rompimento com a sociedade moderna e sua juridicidade tributária de dinâmicas judiciosas, hierarquizadas e cerradas ao monopólio da fala aos detentores de poder-saber oficial. Esse (re)empoderamento constitui um verdadeiro ato de profanação ao paradigma da juridicidade, para romper com a sua procedimentalidade castradora e de solução de conflitos com a produção de dor adicional.

Ainda, a partir do ato de fala, trazendo os nele envolvidos direta e indiretamente e o meio comunitário que os cerca - o qual também é afetado pelo conflito e, portanto, interessado na resolução permite-se que esses indivíduos se conheçam, reconheçam e se encontrem (em uma relação espelhar) através das falas, dos sentimentos, das necessidades e aspirações uns dos outros. Encontrem-se dialogando, discutindo, reconhecendo-se como humanos, demasiadamente humanos, como propunha Slavoj Zizek (2008), remontando a Friedrich Nietzsche com seus erros, mas também com sua imanente capacidade de adaptação e mudança. Nessa linha, leciona Nils Christie:

Qual é o objetivo de insistir em sustentar que temos pontos em comum ou que é possível encontrar humanidade em todas as pessoas? Porque isso é essencial para o controle do controlador. A percepção de outra pessoa como monstro, completamente desprovida de humanidade, facilita que se ignorem certas regras básicas sobre como se relacionar com 
outras pessoas, enquanto seres humanos. A noção de que monstros existem é perigosa para todos, mas especialmente para aquelas pessoas, entre nós, responsáveis pela tarefa de controlar o comportamento das outras pessoas. (CHRISTIE, 2011, p.149).

Assim, entende-se que, subvertendo o monopólio da fala e do poder/saber oficial centralizado de dizer o direito, permite-se que a justiça possa se fazer humana, culturalmente construída e gerida, em um cenário onde os indivíduos se reconheçam como sujeitos, autores e também como objetos dessa mesma justiça. Isso faz com que o peso e a violência, a ira da Justiça seja menos vingativa, já que não trata com espectros maléficos construídos ou com hostis, mas com seres que são todos iguais, apesar das suas singularidades, e demasiadamente humanos. Sendo assim, necessita-se de uma orientação de Justiça que se faça benevolente e orientadora, voltada para o futuro e não para o passado e suas múltiplas verdades.

Nessa esteira, trabalhando a procedimentalidade adotada por um paradigma de Justiça Restaurativa e Comunitária, torna-se necessário trazer um elemento fulcral que, nessa dinâmica dialogal, se pauta não pelo Direito legislado, mas por topos ou topói; ou seja, por um corpo de valores que sejam comuns e comunitariamente aceitos e que permitam aos indivíduos transitarem em seus discursos, saberes e necessidades de recomposição, não ficando atrelados a uma receita ou procedimentalidade determinada hegemonicamente e legitimada pela sua oficialidade. Como bem propõe Boaventura de Sousa Santos,

Esta falta de uniformidad, que puede sorprender lo mismo que escandalizar a quien vea con los ojos etnocéntricos del derecho oficial, no es, sin embargo, caótica. Es determinada por las exigencias normativas y de seguridad, que se van definiendo a lo largo del proceso de prevención o resolución de los conflictos. En Pasárgada, las formas y los requisitos procesales mantienen un estricto carácter instrumental y como tal son usados sólo en la medida en que pueden contribuir para una decisión justa de la causa [...] se desarrolla así, a partir del formalismo elaborado del sistema jurídico estatal, un formalismo popular. (SANTOS, 2007, p.220-21).

Com isso, salienta-se a importância de estarem todos os indivíduos envolvidos e principalmente interessados - e sobremaneira afetados -, em consonância com as regras, ou com os topói e valores que imperam e estão em vigência na vida da comunidade, sendo um verdadeiro e autêntico código de normas (escritas ou não) que está em consonância com a vida real da comunidade e, principalmente, que é partilhado por todos.

Nessa perspectiva, atenta-se para o escopo principal da Justiça Restaurativa, de ser uma alternativa ao paradigma de juridicidade, uma alternativa às dinâmicas que só têm produzido mais sofrimento humano, e não têm resolvido os conflitos, apenas os acirrados.

Acrescente-se, ainda, a importância de representantes da sociedade em meio a esse diálogo, pessoas ligadas a cada uma das partes, tendo em vista que os conflitos não atingem somente os diretamente envolvidos, mas também os indivíduos a eles próximos, que podem e devem trazer seus discursos e contribuir com esse processo restaurativo comunitário e alternativo (LEAL; MACHADO, 2011).

Saliente-se que a Justiça Restaurativa, em sua vertente comunitária - como se pode claramente perceber - propugna por um processo alternativo e sem qualquer regra ou receita predefinida (e este é um importante elemento em sua estrutura simbólica e prática), e que se desenvolve de acordo com o avanço dos diálogos, dos discursos e pretensões apresentadas e suas necessidades. E, sendo assim, preocupa-se com o futuro da comunidade e das relações que a envolvem, e não em reconstituir o status quo ante, ou produzir uma verdade artificial como pretende a processualidade ordinária estatal, com vistas a culpar um, ou (re)vitimizar o outro - ou, ainda, ambos ao mesmo tempo e independentemente da decisão final (LEAL; MACHADO, 2011).

Nessa linha, a partir de João Salm e Margareth Stout (2011), apresentam-se alguns princípios que regem os níveis de análise, intervenção e coprodução de realidades multidimensionais e fragmentárias. Os mencionados autores apontam os cinco principais pontos nodais para processos restaurativos:

1) O conflito como uma oportunidade criativa: os autores argumentam acerca da possibilidade de integração e aprendizagem com a dessemelhança, não havendo a intencionalidade de acabar com o conflito (o que já se tornou pacífico nos estudos criminológicos), já que ele 
é inerente à estrutura social. Uma questão crucial é como se vai trabalhar e encarar, no dia a dia, os conflitos e dessemelhanças, os quais podem ser elementos de inter-relação calcada na aprendizagem mútua.

2) Um segundo princípio a guiar as práticas restaurativas é a Justiça como processo criativo. Esse princípio remete a uma questão fulcral na sociedade moderna - o rompimento com o monopólio de dizer o direito e a abertura da possibilidade de decisões e construções de soluções dialogadas a partir da coaprendizagem frisada no principio anterior, ou seja, de um processo de coprodução de soluções e construção de síntese entre as dessemelhanças e conflitos inerentes à estrutura social.

3) O princípio atinente à ação curativa altera o foco de atuação e preocupação, saindo da esfera individualista do autor do fato e das consequências isoladas daí advindas; apontando para as relações comunitárias que foram quebradas e as consequências dessa ação (tida como delituosa) para a comunidade; perscrutando as causas de tal conduta, o que teria levado tal indivíduo a romper com a comunidade; salientando que, diferentemente da Justiça Criminal Oficial, objetiva-se a reconstrução dos laços e a coconstrução de soluções para as pessoas que tiveram as suas historias separadas pela ação ofensiva.

4) Um quarto elemento principiológico é a responsabilidade holística, que representa a assunção de responsabilidade do indivíduo pelo fato que cometeu, não em face do Estado ou da norma, mas em face das relações comunitárias, incluindo os seres direta e indiretamente envolvidos, afetados material ou simbolicamente. Esse princípio representa, também, a assunção da parcela de responsabilidade da própria comunidade para com o fato ocorrido - uma troca que imbrica a sociedade como um todo. Como os atos lesivos são coproduzidos em uma cadeia de responsabilidades, assim também deve ser a coprodução da sua cura e solução.

5) Como último elemento, a construção da comunidade remete a outros princípios acima indicados, os quais destacam a importância da acepção comunitária da vida em sociedade e, portanto, a sua coprodução a partir da mútua aprendizagem, como também a corresponsabilidade pelos rompimentos e pelas suas soluções. Frisa-se, neste ponto, a importância do potencial construtivo e transformativo que surge da participação social a partir da multidimensionalidade humana calcada no diálogo, a qual permite um processo crescente de sentimento de pertença e que redunda em diminuição dos estranhamentos; ou, pelo menos, em formas diferentes e alternativas de trabalhar com esses estranhamentos e diferenças.

Percebe-se o quanto é difícil separar as esferas de atuação ou delimitação de sentido entre os princípios (que não são taxativos, sequer conformam um rol fechado), que se permeiam e formam um complexo de sentido inter-relacionado e multidimensional. Um complexo que se propugna por dinâmicas de juridicidade que não se resumam a definir respostas prontas e que partam de um saber superior; mas que se construam de forma partilhada, reconhecendo os saberes que podem colaborar, cada um da sua maneira, para a resolução dos conflitos. Nesse sentido, aponta Eugenio Raul Zaffaroni:

Dessa perspectiva, pode-se afirmar que a idade media não terminou e está longe de terminar. Dependerá da capacidade humana de transformação do conhecimento a substituição da inquisitio, algum dia, pelo dialogus, em que o saber não seja mais o dominus e sim o frater. Porem, a mera perspectiva desta possível mudança civilizatória mostra a formidável medida em que o problema transcende o campo do penal para converter-se em uma questão da cultura universal. Pretender ignorar esta dimensão e resolver a questão como um simples problema de política criminal, passível de ser liquidado em poucas páginas, é uma ingenuidade insustentável, ou melhor, uma limitação de conhecimento inadmissível por seu altíssimo nível de isolamento com relação aos outros saberes. (ZAFFARONI, 2007, p.42).

A fim de possibilitar uma maior capacidade de compreensão da Justiça Restaurativa, aponta-se como importante elemento neste adensamento teórico o fato de que essa forma de justiça não se resume à resolução de conflitos, mas a ações que visam 
reconstruir a vida em comunidade, sendo uma ética comunitária e emancipatória voltada para o futuro da vida comunitária.

Acentua-se que tal produção de juridicidade alternativa não se dá de forma espontânea e sem razão, mas sim diante da profunda crise (em especial epistêmica e de legitimidade - isso sem falar na incapacidade prática em resolver os conflitos de forma satisfatória) em que se encontra a juridicidade estatal oficial brasileira, cuja historicidade apresenta a ocorrência de diversos déficits.

Nessa perspectiva, as juridicidades alternativas (é provável que os códigos alternativos sempre tenham existido, mas a dinâmica oficial provocava a sua invisibilidade) passam a ganhar visibilidade e se tornar uma alternativa real e mais eficiente, além de menos custosa (em termos econômicos, temporais e pessoais), demonstrando serem juridicidades sombras, à espreita das falhas na Justiça dos Homens Médios. Assim se conceitua a micro-governança da Justiça, ou Justiça Nodal, como referem Slakmon e Oxhorn:

As estruturas de governança nodal têm uma conformação descentralizada, em que o poder e a responsabilização são distribuídos de acordo com uma relação de parceria baseada no conhecimento entre os atores estratégicos (ou "nós”). As capacidades e técnicas específicas de cada nó são mobilizadas por meio de estruturas de compartilhamento do poder que favorecem o uso do conhecimento local para maximizar a eficiência da administração e o processamento de questões específicas. Em termos mais específicos, a governança nodal é um construto da teoria da rede contemporânea que explica como uma serie de atores que atuam no âmbito de sistemas sociais interagem em redes para governar os sistemas que habitam. Um nó, segundo nossa concepção, é um ponto (no interior de um sistema social complexo), em que conhecimento, capacidade e recursos são mobilizados para o gerenciamento de uma sequência de eventos. (SLAKMON; OXHORN, 2006, p.34).

Reafirmando a capacidade e potencialidade da existência de outros marcos sócio-regulatórios e, sobretudo, emancipatórios, das dimensões de sociabilidade que partem dos indivíduos envolvidos e principais afetados, Slakmon e Oxhorn (2006, p. 35) fazem a seguinte afirmação:
Embora não sejam especialistas em serviço social, psicologia nem direito - campos tradicionais em que a resolução de conflitos é uma competência profissional - os residentes da comunidade são especialistas nos problemas cotidianos e na realidade em que esses problemas se situam e, portanto, têm o conhecimento relevante necessário para sua solução. (SLAKMON; OXHORN, 2006, p.35).

É da periferia deste sistema mundo (mas não pertencente a ele) que tem de irromper a cidadania como poder de atuação/participação/modificação, a fim de viabilizar um projeto de juridicidade alternativa comunitária e emancipatória, tendo em vista que, como afirmam Slakmon e Oxhorn (2006, p. 43), "quando as pessoas têm um problema a ser resolvido, ou um conflito de interesses a mediar, têm menor probabilidade de recorrer às instituições estatais para tanto e obter justiça". Isso demonstra a total falibilidade procedimental e conceitual, e também em dar conta dos objetivos declarados (ANDRADE, 2003) que legitimam a juridicidade punitiva moderna estatal e oficial ${ }^{6}$. Nessa linha, aponta a professora Lola Aniyar de Castro (2005, p.145):

A via mais profícua para a libertação do homem é o desencantamento, o enfrentamento com a realidade, oculta ou evidente. No caminho da ocultação, os caminhantes mais corriqueiros são as palavras. Se elas não são constatativas, mas performativas, criam uma realidade falsa e superposta. São boa parte da ideologia-ocultação. Dizer que a justiça é participativa é performação, e não constatação.

Com isso, propugna-se a micro-justiça e que seja proveniente e aplicada no interior de culturas e grupos nos quais surgem os conflitos; que proponha e produza rompimentos de hierarquias, a partir de relações dialogais e horizontalizadas, e que tenha por intento a reparação e produção de realidades presentes e futuros edificantes, libertadores e emancipatórios, ao invés de se preocupar com a reconstrução do status quo ante e em determinar objetos de

\footnotetext{
${ }^{6}$ Neste ponto é de especial relevância a distinção que a professora Vera Regina Pereira de Andrade (2003) faz das funções declaradas do sistema penal, que se dividem em prevenção geral (dissuasória) e prevenção especial (ressocialização), funções de que o sistema não dá conta. De outro lado, aponta as funções latentes e reais desta mesma prevenção geral, que são a seletividade penal e a gestão das ilegalidades de forma desigual; e a prevenção especial, que se manifesta pelo puro e simples isolamento de certo tipo de indivíduo, que pode ser muito bem individualizado como pertencente a certa parcela da sociedade, um isolamento com caráter eminentemente classista.
} 
responsabilização e níveis de responsabilidade (SLAKMON; OXHORN, 2006).

Por fim, entende-se que tal projeto não deve ser pensado como uma dinâmica pronta a ser colocada em prática de cima para baixo, mas sim como um processo de construção cultural, política e social que, em grande medida, requer tempo e capital humano comum e/ou científico (na forma de consciência), e que se desenvolve a partir de diversas dimensões: se entrecruzando, auxiliando e ampliando a infiltração na vida das pessoas envolvidas e das comunidades como figuras coletivas de sociabilidade; permanecendo como processo aberto ao diálogo e a novas estratégias que amplifiquem a sua capacidade empoderadora e produzam uma racionalidade do senso comum insurgente e emancipatória (SANTOS, 1987, p.89).

Remonta-se, ainda, o que Brenda Morrison (2005) já vem propondo, destacando-se que o metaprojeto de justiça restaurativa, no sentido de uma juridicidade alternativa, faz parte de um projeto mais audacioso e que não se resume à juridicidade, mas se estrutura em uma refundação da concepção de política, culturalidade, ciência ou mesmo senso comum. Já Boaventura Santos propõe pilares para a revolução paradigmática $(1987 ; 1989 ; 2000 ; 2006)$ e para a construção de uma sociedade pós-moderna, no sentido de ultrapassagem das mazelas que os paradigmas modernos têm produzido e intensificado.

Com isso, propugna-se por um paradigma de juridicidade que se faça voltado para a comunidade e a partir da própria comunidade; que seja orientado a partir do exorcismo do espírito da vingança (Zarathos), que se dá a partir da reaproximação dos indivíduos e da retomada da capacidade de dialogar e de reconhecer no outro um sujeito igual aos demais, com sua singularidade humana; que devolva a cada indivíduo a capacidade de ver no outro um pouco de si mesmo, como propõe Emmanuel Lévinas (1997), conjurando assim o espírito do perdão (Zadkiel); e que, a partir disso, a justiça se faça coproduzida e voltada para o futuro da comunidade, das relações humanas orientadas pela capacidade de dialogar, partilhar conhecimento, experiências e expectativas - a partir do perdão como figura simbólica e material construtiva e performativa de novas vidas.

\section{Considerações finais}

Em sede de aportes conclusivos, trabalha-se com um intento de abertura/ruptura e tensionamento do paradigma da segurança e justiça hegemônica, que se faz com um complexo eminentemente simbólico e um complexo conceitual, os quais se orientam pela ideia de isolamento do sujeito cognoscente e em uma suposta neutralidade científica e axiológica, o que lhe tem permitido, a partir desse afastamento, dinamizar as suas estratégias e produzir e reproduzir vítimas e dores que se fazem sistêmicas e politicamente legitimadas por discursos periculosistas de toda ordem, ao passo que o seu fracasso e a sua incapacidade, que são mais epistêmicos que materiais, são justificados por diversos argumentos que vão da insuficiência material a um suposto incremento da criminalidade - sendo este um constructo argumentativo falacioso, como se demonstrou acima.

Nessa esteira, um paradigma de juridicidade é entendido a partir da proposta de Boaventura Sousa Santos (2010), que o define como um constructo cultural que, imanentemente, é construído a partir de três elementos básicos: a retórica, a burocracia e a violência. É com base nesses elementos que se constrói a variabilidade das estruturas jurídicas modernas, de acordo com a prioridade que é dada a cada elemento dessa complexa equação e eterno binômio regulação/emancipação.

A partir disso, buscou-se demonstrar o quanto o paradigma de justiça oficial e estatal tem se feito como um complexo de signos e símbolos que se pautam por uma estrutura burocrática e imanentemente violenta, calcada em um aparato simbólico criador de estranhos e legitimador de sua resposta vingativa. Confirmou-se, assim, a incorporação do espírito de Zarathos ao sistema penal estatal oficial, o qual se volta para o passado e para a reconstituição de uma suposta verdade real. Isso acontece para que elementos cognitivos possam conformar uma definida verdade real e justificar a resposta punitiva, que seria a dinâmica prioritária de pacificação social, por mais paradoxal que isso possa efetivamente ser - a pacificação pela violência oficializada.

De outro lado, apontam-se dinâmicas de juridicidade que se fazem inter-relacionais e abertamente dialogais a partir de relações horizontalizadas, e propugna-se por elas. Pautadas por estruturas concei- 
tuais baseadas em constructos comuns, partilhados os topói - fazem-se estruturas conceituais contextualizadas e em consonância com a vida comunitária, aptas a corresponder às necessidades relacionais e seus conflitos normais e imanentes à vida em grupo.

É importante lembrar que a criação/organização material e procedimental dessas estruturas deve ser feita a partir de uma orientação democrática e inclusiva, desburocratizada e desinstitucionalizada; que se deve olhar com os olhos da comunidade os conflitos do dia a dia, já que eles são causados e, assim, integrados por indivíduos da própria comunidade. Portanto, a desestruturação social é produzida por indivíduos que partilham e mantêm (ainda que depois da agressão e conflito) a sua condição de humanidade e aproximação; assim como tal aproximação é partilhada por quem também irá atuar e contribuir para a resolução do conflito.

Sendo assim, o processo multidimensional e complexo de resolução de conflitos a partir dos postulados e orientações da Justiça Restaurativa em sua vertente comunitária se faz a partir da conjuração do espírito do perdão (Zadkiel), que permite à justiça deixar o conflito para trás (o qual não deixará de fazer parte da historicidade). Além disso, possibilita que os indivíduos direta e indiretamente envolvidos, assim como também a comunidade, possam se voltar para o futuro e para a projeção e restauração de expectativas e estratégias de satisfação, orientados pela cooperação e corresponsabilidade.

Por derradeiro, entende-se que as dinâmicas de juridicidade não dependem da organicidade de que emanam, mas sim da sua capacidade de regular, emancipar, organizar e ser um constructo que tenha condições materiais e simbólicas de dar estruturação para a sociedade que se propõe a emancipar. Parte-se, assim, de uma perspectiva de subversão dos postulados da burocracia e da violência pelo retorno da retórica em que subjaz a capacidade de diálogo e relações horizontalizadas de resolução de conflitos, em uma justiça desburocratizada, desinstitucionalizada, e que se faz/atua orientada à inserção e contextualização no meio do qual emerge. Essa forma de justiça emana seus constructos jurídicos normativos a partir de topói de conhecimento e reconhecimento comum, sendo, assim, uma ordem jurídica partilhada e em consonância com a vida em comunidade em sua constante mutação e complexidade de relações.

\section{Referências}

AGAMBEN, Giorgio. Homo Sacer: o poder soberano e a vida nua. Belo Horizonte: editora UFMG, 2007.

ANDRADE, Vera Regina Pereira. A ilusão da segurança jurídica: do controle da violência à violência do controle penal. Porto Alegre: Livraria do Advogado, 2003.

ANIYAR DE CASTRO, Lola. Criminologia da libertação. Tradução de Sylvia Moretzsohn. Rio de Janeiro: Revan/ICC, 2005.

BARATTA, Alessandro. Criminologia crítica e crítica do Direito Penal: introdução à sociologia do direito penal. Rio de Janeiro: Freitas Bastos/ ICC, 1999.

BATISTA, Vera Malaguti. Difíceis ganhos fáceis: drogas e juventude pobre no Rio de Janeiro. Rio de Janeiro: Revan/ ICC, 2003.

Introdução crítica à criminologia brasileira. Rio de Janeiro: Revan, 2011.

BAUMAN, Zygmunt. O mal-estar da pós-modernidade. Tradução de Mauro Gama e Claudia Martinelli Gama. Rio de Janeiro: Zahar, 1998.

Modernidade líquida. Tradução de Plínio Dentzien. Rio de Janeiro: Zahar, 2001.

Legisladores e intérpretes. Tradução de Renato Aguiar. Rio de Janeiro: Zahar, 2010.

BECKER, Howard S. Outsiders: estudos de sociologia do desvio. Trad. Maria Luiza Xavier de Barros. Rio de Janeiro: Zahar editor, 2008.

BRAITHWAITE, J. Entre proporcionalidade e a impunidade: confrontação-verdade-prevenção. In: SLAKMON, C.; et al. (Orgs.). Novas direções na governança da justiça e da segurança. Brasília-DF: Ministério da Justiça, 2006a, p.371-388.

Emancipação e esperança. In: SLAKMON, C.; et al. (Orgs.). Novas direções na governança da justiça e da segurança. Brasília-DF: Ministério da Justiça, 2006b. p.389-410.

CAVALHO, Salo de. A política criminal de drogas no Brasil: estudo criminológico e dogmático. Rio de Janeiro: Lúmen Juris, 2007.

Anti-manual de criminologia. Rio de Janeiro: Lúmen Juris, 2008a.

O papel dos atores do sistema penal na era do punitivismo. Rio de Janeiro: Lúmen Juris, 2010.

Memória e esquecimento nas praticas punitivas. In: GAUER, Ruth Maria Chittó (Org.). Criminologia e sistemas jurídico-penais contemporâneos. Porto Alegre: EDIPUC/RS, 2008b. p.57-31. 
CHRISTIE, Nils. Uma razoável quantidade de crime. Tradução de André Nascimento. Rio de Janeiro: Revan/ICC, 2011.

DEL OLMO, Rosa. A américa latina e sua criminologia. Tradução de Francisco Eduardo Pizzolante. Rio de Janeiro: Revan/ICC, 2004.

JACCOUD, M. Princípios, tendências e procedimentos que cercam a justiça restaurativa. In: BRASIL. Ministério da Justiça. Justiça Restaurativa. Programa das Nações Unidas para o desenvolvimento. Brasília: 2005. p.163-188.

LEAL, Jackson da Silva. Vulnerabilidades e sobrecargas de punição no direito penal do menor. Revista Intratextos, v. 3 n.1, Rio de Janeiro, 2011. p.143-166.

.; MACHADO, Lucas Fagundes. Política Judiciária brasileira: da produção de cidadania à cooptação sistêmica. Revista Brasileira de Políticas Públicas, v.2 n. 1. Brasília: UNICEUB, 2012. Disponível em: <http://www. publicacoesacademicas.uniceub.br/index.php/RBPP/article/ view/1677/156 9>. Doi: 10.5102/rbpp.v2i1.1677

.; SALM, João. A justiça restaurativa: multidimensionalidade humana e seu convidado de honra. Revista Sequência: estudos jurídicos e políticos, v.33, n.64, Florianópolis: PPGD, 2012.

LEVINAS. Emmanuel. Entre nós: ensaios sobre a alteridade. Tradução de Pergentino Stefano Pivatto; et al. Petrópolis/ RJ: Vozes, 1997.

MORRISON, Brenda. Justiça restaurativa nas Escolas. In: BRASIL. Ministério da Justiça. Justiça Restaurativa. Programa das Nações Unidas para o Desenvolvimento (PNUD), 2005. p.295-319.

OST, François. O tempo do direito. Tradução de Maria Fernanda Oliveira. Lisboa: Instituto Piaget, 1999.

SALM, João. Co-produced restorative justice: the possibility of implementing restorative justice principles in South Brazil. Arizona State University, Tempe, AZ, 2009.

; STOUT, Margareth. What restorative justice might learn from administrative theory. Contemporary Justice Review, v.14, n.2, p.203-225, 2011.

SANTOS, Boaventura de Sousa. A crítica da razão indolente: contra o desperdício da experiência. São Paulo: Editora Cortez, 2000.

A gramática do tempo: para uma nova cultura política. São Paulo: Editora Cortez, 2006.

Sociología jurídica crítica: para un nuevo sentido común en el Derecho. Madrid/España - Bogotá/Colombia: Editorial Trotta / ILSA, 2010.

Introdução a uma ciência pós-moderna. Rio de Janeiro: Graal, 1989.
Um discurso sobre as ciências. Porto: Edições Afrontamento, 1987.

SLAKMON, Catherine; OXHORN, Phillip. Micro-justiça, desigualdade e cidadania democrática: a construção da sociedade civil através da justiça restaurativa no Brasil. In: SLAKMON, C. et al. (Org.). Justiça restaurativa. Programa das Nações Unidas para o Desenvolvimento - PNUD, 2005. p.189-211

.; _ _ O O poder da atuação dos cidadãos e a micro-governança da justiça no Brasil. In: SLAKMON, C.; et al. (Orgs.). Novas direções na governança da justiça e da segurança. Brasília-DF: Ministério da Justiça, 2006. p.31-57

YOUNG, Jock. A sociedade excludente: exclusão social, criminalidade e diferença na modernidade recente. Trad. Renato Aguiar. Rio de Janeiro: ICC/Revan, 2002.

ZIZEK, Slavoj. A visão em paralaxe. Tradução de Maria Beatriz de Medina. São Paulo: Boitempo, 2008.

ZEHR, Howard. Trocando as lentes: um novo foco sobre o crime e a justiça. Tradução de Tônia Van Acker. São Paulo: Palas Athena, 2008.

; TOEWS, B. Maneiras de conhecer para uma visão restaurativa de mundo. In: NOVAS Direções na Governança da Justiça e da Segurança. Brasília: Ministério da Justiça, 2006. p.419-432.
Recebido em: 7 de junho de 2012 Aceito em: 17 de setembro de 2012 